Arq. Bras. Med. Vet. Zootec., v.66, n.4, p.1033-1038, 2014

\title{
Avaliação da migração das células progenitoras após terapia da tendinite equina
}

\author{
[Migration evaluation of progenitor cells after treatment of equine tendinitis] \\ P.G.G. Oliveira, A.M. Carvalho, A.L.M. Yamada, L. Maia, N.P.P. Freitas, M.J. Watanabe, \\ F.C. Landim-Alvarenga, A.L.G. Alves* \\ Universidade Estadual Paulista - FMVZ-Unesp - Botucatu, SP
}

\begin{abstract}
RESUMO
A terapia celular vem sendo utilizada com resultados promissores no tratamento da tendinite equina, entretanto ainda existem dúvidas quanto à persistência e ao comportamento dessas células quando implantadas no local da lesão, e quanto à sua migração para outros focos inflamatórios. O objetivo deste estudo foi avaliar a marcação das células-tronco mesenquimais (CTMs) com nanocristal antes e após o implante em lesões tendíneas experimentais do tendão flexor digital superficial (TFDS) de equinos, bem como observar a possibilidade de migração das CTMs marcadas para outro foco de lesão, o membro contralateral do mesmo animal. Para isso, foi realizada a indução de lesão experimental no TFDS em ambos os membros torácicos de cinco equinos e, após sete dias, foram implantadas as CTMs autólogas marcadas com o nanocristal Qtracker 655 em um dos membros dos animais. Após sete dias do implante, foi realizada a biópsia tendínea para posterior avaliação histopatológica, utilizando-se microscopia com fluorescência. Também foi realizado o teste de viabilidade celular antes e após a incubação com o nanocristal. As CTMs marcadas e injetadas no tecido tendíneo mantiveram sua fluorescência sete dias após seu implante, e não ocorreu migração para o membro contralateral. O uso do nanocristal para a marcação das CTMs derivadas da medula óssea equina mostrou-se efetivo pelo fato de essa nanopartícula não ter alterado a viabilidade celular e por ela ter permanecido ativa durante o período implantado.
\end{abstract}

Palavras-chave: equino, células-tronco mesenquimais, nanocristal, tendinite, migração

\begin{abstract}
Cell therapy has been used with promising results in the treatment of equine tendinitis. However, there are still doubts about the persistence and behavior of these cells implanted in the injured tissue and their migration to other inflamed sites. The aim of this study was to evaluate the labeling of mesenchymal stem cells (MSCs) with nanocrystals before and after implantation in experimental tendinitis of the superficial digital flexor tendon (SDFT) of horses, observing the migration possibility of MSCs marked to another lesion, performed on the contralateral limb of the same animal. An experimental lesion was induced in SDFT in both forelimbs of five horses, and after seven days autologous MSCs labeled with Qtracker ${ }^{\circledR} 655$ were implanted in one member of the animals. Tendon biopsy was performed for subsequent histopathological evaluation using fluorescence microscopy seven days after the implant. Cell viability test was also performed before and after incubation with the cell labeling kit. MSCs labeled and injected into the tendon tissue maintained their fluorescence seven days after their implantation and there was no migration to the contralateral limb. The use of nanocrystals for labeling MSCs was effective because it does not alter cell viability and remains active during the experimental period.
\end{abstract}

Keywords: equine, mesenchymal stem cells, nanocrystal, tendinites, migration

Recebido em 5 de fevereiro de 2013

Aceito em 11 de fevereiro de 2014

*Autor para correspondência (corresponding author)

E-mail: anaalves@fmvz.unesp.br 


\section{INTRODUÇÃO}

A tendinite do tendão flexor digital superficial (TFDS) é uma importante enfermidade que acomete a espécie equina. Apresenta alto índice de recidiva e pode resultar na diminuição do desempenho atlético e até mesmo no afastamento do animal de suas atividades esportivas. São várias as metodologias terapêuticas disponíveis para o tratamento da tendinite. No entanto, ainda há deficiência quanto à regeneração do tecido lesado proporcionada por essas terapias, resultando na formação de um tecido cicatricial funcionalmente deficiente, quando comparado ao tendão saudável, o qual predispõe os animais à recidiva (Oliveira et al., 2011).

Com o desenvolvimento da biotecnologia na medicina veterinária, a terapia celular vem sendo utilizada com resultados promissores, tanto em avaliações clínicas quanto experimentais na terapia da tendinite equina. Um recente estudo demonstra a diminuição da taxa de recidiva após o implante intralesional das células-tronco mesenquimais (CTMs) derivadas da medula óssea quando comparado a terapias convencionais na tendinite de ocorrência natural (Godwin et al., 2012). Também existem avaliações experimentais que demonstram a melhora histopatológica e o aumento da concentração de colágeno tipo I do tecido tendíneo tratado com as CTMs derivadas de medula óssea (Oliveira et al., 2011).

O uso das CTMs para a terapia da tendinite é baseado na ação dessas células após seu implante. Acredita-se que tais células possam sofrer diferenciação fenotípica compatível com as células do tecido tendíneo (tenócitos) ou ser capazes de produzir a matriz extracelular (MEC) do tendão equino. Entretanto, estudos recentes sugerem que a função principal das CTMs seja de modo indireto, pelo seu efeito trófico, por meio do qual, após o implante das células, há produção de diversas proteínas bioativas, como os fatores de crescimento, os fatores antiapoptose e vários agentes quimiotáticos. Outra importante ação igualmente relacionada à terapia celular é a sua função anti-inflamatória (Alves et al., 2011).

A migração das CTMs tem sido descrita na tendinite equina com a marcação dessas células com o Green Fluorescent Protein (GFP), por meio da infusão do plasmídeo pCAG-EGFP-1 por eletroporação (Guest et al., 2008). No entanto, existem poucas informações quanto ao potencial e aos fatores que regulam essa migração celular. Sabe-se que a habilidade de atração dessas células aos locais de lesão deve-se à inflamação existente no local lesado. A inflamação envolve a produção de um grande número de moléculas, incluindo proteínas, que têm como ação a adesão entre as células. Essas proteínas atuam como sinalizadores, atraindo umas às outras, e as ativam de diversas formas, assim como seus receptores. As proteínas envolvidas com o tropismo das CTMs ao local inflamado aparentam ser semelhantes ao mecanismo de quimiotaxia, que atrai os leucócitos às regiões lesadas e inflamadas (Satake et al., 2003).

Atualmente, um novo modelo de marcação celular utiliza os pontos quânticos (QDs), que são nanocristais semicondutores caracterizados por alta fotoestabilidade e excitação de um único comprimento de onda. A interiorização da fluorescência é feita passivamente, mediada por endocitose no citoplasma das células, e pode permanecer ativa por pelo menos quatro gerações celulares; ademais, algumas células se mantêm marcadas por até oito semanas (Rosen et al., 2007). Um recente estudo utilizou os nanocristais fluorescentes Q-Tracker para a identificação das células mononucleares implantadas em defeitos ósseos, sete dias após o tratamento (Oliveira et al., 2010). A vantagem em se utilizarem os pontos quânticos para a marcação das CTMs é sua citocompatibilidade. Essas nanopartículas são resistentes às degradações química e metabólica, apresentam uma elevada fotoestabilidade e têm efeitos citotóxicos mínimos, ao contrário da marcação com GFP. Além disso, os pontos quânticos apresentam tais efeitos citotóxicos dose-dependentes, o que permite que a viabilidade celular possa ser otimizada e, portanto, limita a exposição das CTMs a baixas concentrações de QDs (MullerBorer et al., 2007).

Diversos estudos já demonstraram a viabilidade de marcação das CTMs com os QDs (Rosen et al., 2007; Collins et al., 2012). No entanto, ainda faltam dados consistentes na literatura referentes ao comportamento dessas células quando utilizadas em tratamentos de tendinites experimentais e, consequentemente, à possibilidade de migração para outras áreas de 
lesão e inflamação. Em estudo realizado por Carvalho et al. (2013), foi possível encontrar CTMs derivadas do tecido adiposo marcadas com QDs na corrente sanguínea após uma semana do tratamento de tendinite experimental. Em contrapartida, Guest et al. (2010) apenas confirmaram a migração de células embrionárias, ao afirmarem que em 90 dias as CTMs não foram capazes de migrar quando aplicadas em tendinites experimentais. Desta forma, em meio a essas informações controversas, o objetivo do presente trabalho foi novamente avaliar a eficácia de marcação do nanocristal (Qtracker® 655 Cell Labeling Kit, Invitrogen, USA) em CTMs derivadas da medula óssea de equinos, porém visando a sua utilização no tratamento de tendinites experimentais, bem como analisar a possibilidade de migração dessas células para o membro contralateral, quando utilizado como controle.

\section{MATERIAL E MÉTODOS}

Foram utilizados cinco equinos de ambos os sexos, com idade entre dois a cinco anos, sendo todos hígidos e da raça Mangalarga. Para o uso dos animais na presente avaliação experimental, foi necessária a aprovação pela Câmara de Ética em Experimentação Animal, protocolo número 213/2008.

Os animais foram submetidos à punção da medula óssea na região da quinta esternebra para coleta do sangue medular e posterior isolamento e cultivo das CTMs. A indução da lesão experimental foi estabelecida como tempo zero do experimento (D0). Todos os membros torácicos dos cinco animais foram submetidos à injeção intratendínea de $1 \mathrm{~mL}$ de colagenase tipo 1 (Collagenase type I, Invitrogen, USA) $(2,5 \mathrm{mg} / \mathrm{mL})$ no TFDS para a indução da tendinite. Os membros torácicos dos animais foram distribuídos em dois grupos de cinco membros cada (GA e GB), e os tendões lesados foram tratados conforme os grupos: GA tratamento e GB - controle. No sétimo dia do experimento (D7), o GA recebeu o implante das células-tronco mesenquimais marcadas com nanocristal Qtracker 655. Todos os animais (GA e GB) foram submetidos à biópsia no $14^{\circ}$ dia do experimento (D14 - sete dias após o implante celular). Retirou-se um pequeno fragmento da área lesada do TFDS, o qual foi observado em microscopia de fluorescência.
A punção medular e o isolamento da fração mononuclear foram realizados conforme prévia descrição (Oliveira et al., 2011). A coleta de sangue medular foi feita com um mês de antecedência, no início do experimento, para o adequado tempo de isolamento, cultivo e expansão das CTMs implantadas. $\mathrm{O}$ isolamento e a expansão das CTMs foram realizados mediante cultivo das células mononucleares previamente obtidas e mantidas em placas de cultura de $25 \mathrm{~cm}^{2}$ em estufa a $37^{\circ} \mathrm{C}$ e $4 \%$ de $\mathrm{CO}_{2}$. O meio de cultivo utilizado foi o DMEM Knockout contendo $10 \%$ de soro fetal bovino. Este foi trocado a cada 48 horas até a confluência de $80 \%$ da placa de cultura, quando as CTMs foram submetidas ao tratamento com tripsina (passagem) e lavadas em PBS para imediato uso. Foi realizado o teste de viabilidade celular pré e pós-incubação com o marcador celular utilizando-se câmara de Neubauer e azul de Tripan, conforme descrição de Oliveira et al. (2011).

A caracterização imunofenotípica das CTMs derivadas da medula óssea não foi realizada no presente estudo, já que, em estudo anterior realizado por Maia et al. (2013) no mesmo laboratório, utilizou-se o mesmo protocolo de isolamento das CTMs e obteve-se marcação média de $95,39 \%$ para CD 90 (clone OX7, Caltag LaboratoriesVR , USA), 69,43\% para CD44 (clone 581/CD34, BDVR, USA) e ausência de expressão para CD34 (clone CVS18, abD SerotecVR, UK), o que embasou a utilização das CTMs derivadas da medula óssea neste experimento.

No momento do implante celular (em D7), as CTMs previamente isoladas, cultivadas e expandidas foram incubadas por 60 minutos com o nanocristal Qtracker 655 (Cell labelling kits, Invitrogen, USA), seguindo as instruções do fabricante, para posterior aplicação.

O implante das CTMs marcadas foi realizado no grupo tratado (GA) após preparação cirúrgica local padrão, com a sedação (Sedomin 10\% LK - König, Brasil) (xilazina 1,1mg/kg, IV), tricotomia, antissepsia, bloqueio anestésico local com lidocaína (lidocaína $2 \%$ s/ vasoconstritor Cristália, Brasil) sem vasoconstritor. As células marcadas com o nanocristal foram suspensas em $0,5 \mathrm{~mL}$ de PBS e implantadas imediatamente após sua incubação. O implante foi realizado 
com o auxílio da imagem ultrassonográfica e agulha hipodérmica $30 \times 0,8 \mathrm{~mm}$, posicionada no centro da lesão do TFDS. O membro contralateral não recebeu nenhum tipo de terapia e foi denominado grupo controle (GB). Optou-se pela não aplicação de nenhum tipo de placebo no grupo controle, já que o PBS foi utilizado apenas para a suspensão das CTMs, permitindo, assim, a sua aplicação, e o objetivo do trabalho não foi acompanhar respostas inflamatórias ou reparação tendínea, e sim a viabilidade de marcação do nanocristal e sua possível migração. Os membros que foram definidos como tratado (GA) ou controle (GB) foram escolhidos aleatoriamente no momento do tratamento.

Transcorridos 14 dias após a indução da lesão (D14), foram realizadas as biópsias dos TFDS de ambos os membros torácicos de todos os animais (GA e GB), com o objetivo de avaliar a eficácia de marcação das CTMs com os nanocristais in vivo após sete dias de seu implante, bem como a possível migração dessas células para o membro contralateral (GB). A descrição da biópsia tendínea é idêntica à previamente descrita por Oliveira et al. (2011). Após esse período, cortes de sete micrômetros de espessura foram obtidos em criostato das amostras congeladas e distendidos em lâminas histológicas. Esses cortes foram corados pelos métodos de hematoxilinaeosina (HE) e analisados por microscopia óptica. Foi também realizada a avaliação direta, sem nenhum tipo de coloração, em microscópio de fluorescência (Leica, microscópio de microdissecção), nos filtros vermelho e azul.

\section{RESULTADOS E DISCUSSÃO}

Foram obtidos entre 35 a $40 \mathrm{~mL}$ de sangue medular por punção da quinta estérnebra. O isolamento das células mononucleares, assim como a expansão das células progenitoras ao longo de duas passagens (30 dias de cultivo), possibilitou o implante de um número que variou de $1,5 \times 10^{6}$ a $2,5 \times 10^{6}$ de CTMs. A diferença alcançada neste estudo no número de CTMs obtidas após seu cultivo é compatível com a descrição feita por Smith et al. (2003), que descreveram uma ampla variação no número de células obtidas entre diferentes amostras durante o cultivo. Inferiu-se que essa variação não altera a viabilidade de marcação e a possibilidade de migração, visualizada em biópsia, das CTMs. O número de células aplicadas no tratamento de tendinites equinas ainda é incerto, porém sugere-se que a dose entre $10^{6}$ e $10^{7}$ células por lesão tratada seja suficiente para que os efeitos quimiotáxicos, anti-inflamatórios e bioativos das CTMs sejam amplamente demonstrados, resultando em uma implicação positiva sobre a reparação (De Mattos Carvalho et al., 2013).

A indução da lesão TFDS foi realizada com sucesso em todos os animais, os quais apresentaram claudicação, aumento de temperatura local e sensibilidade. No dia do implante celular (D7), foi realizada a ultrassonografia no local da indução da lesão antes da instituição da terapia e foi observada imagem ultrassonográfica hipoecoica na região central do TFDS. Este achado ultrassonográfico foi compatível com a inflamação tendínea descrita em estudo prévio sobre indução da tendinite equina (Yamada et al., 2009).

A marcação das CTMs com nanocristais foi realizada previamente à aplicação das células nas lesões tendíneas. $\mathrm{O}$ protocolo se mostrou adequado, e, após o período de 60 minutos necessário à entrada do marcador no citoplasma das células, estas, já em suspensão, foram levadas ao microscópio de fluorescência, sendo confirmada a sua marcação (Fig. 1). Não foi realizada avaliação quantitativa das CTMs marcadas com o nanocristal, entretanto há dados, segundo o fabricante, de que a marcação do produto é superior a $97 \%$. O teste de viabilidade celular realizado por meio da técnica de exclusão com o azul de Tripan pré e pós-marcação com o nanocristal Q-tracker 655 demonstrou resultado médio de viabilidade celular de $87 \%$ e $80 \%$, respectivamente. Estes resultados são compatíveis com o descrito por Oliveira et al. (2009), que observaram viabilidade de $98 \%$ nas CTMs não marcadas e $97 \%$ nas CTMs marcadas, e demonstram a efetividade desse tipo de marcação quanto à não alteração da viabilidade celular e fotoestabilidade. Conclui-se que esse marcador não possui ou apresenta baixa ação citotóxica das células-tronco, sendo citocompatível e viável para o uso com as CTMs (Carvalho et al., 2013). 
A)
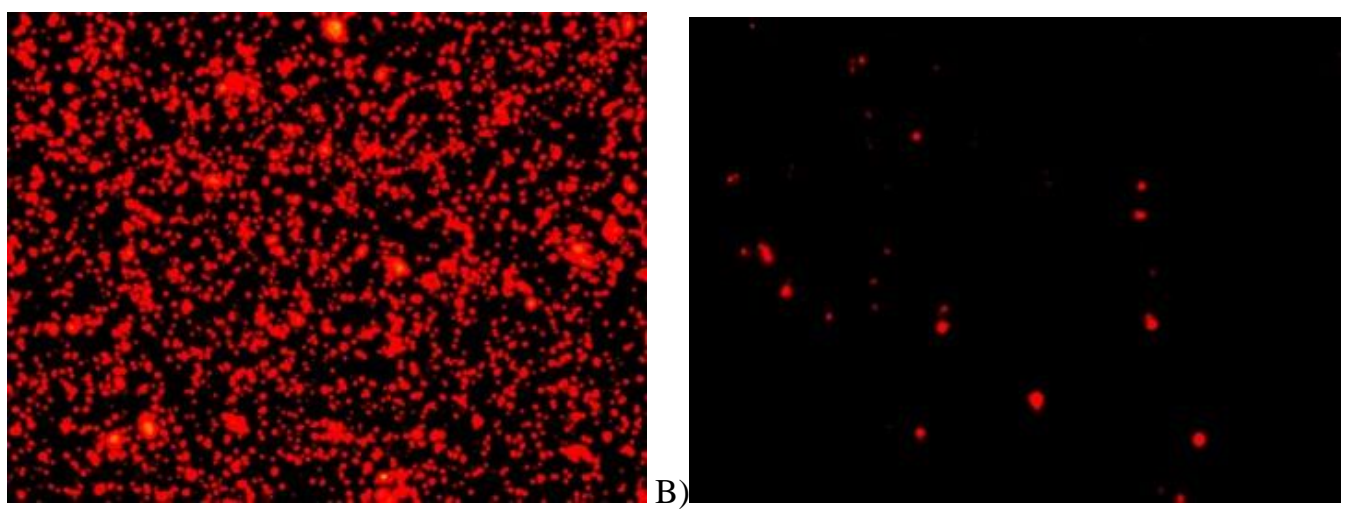

Figura 1. Imagem das CTMs marcadas com o nanocristal Qtracker 655 (pontos vermelhos) observado em microscopia com fluorescência. A) Imagem das CTMs em suspensão em meio de cultura (in vitro) logo após a incubação com o marcador (aumento de 200x). B) Imagem das CTMs nos tendões do grupo tratado, após a biópsia, sete dias após o implante (aumento de 400x).

Os cortes histopatológicos corados com $\mathrm{HE}$ confirmaram a presença da lesão em todos os tendões coletados, por meio da alteração da organização tecidual, a perda do alinhamento das fibras tendíneas, a presença de infiltrado inflamatória e a presença de vasos e edemas intratendíneos identificados como perda da continuidade tecidual. Não houve diferença histopatológica entre os grupos tratado e controle. Isso se deve possivelmente ao tempo relativamente curto de avaliação, pois um intervalo de tempo maior se faz necessário para que se possa realizar uma adequada comparação e avaliação do tecido neoformado entre os diferentes grupos experimentais. Oliveira et al. (2011) observaram melhora histopatológica dos tendões tratados com as células mononucleares derivadas da medula óssea comparados ao grupo de tendões que não receberam terapia, entretanto o tempo pós-terapia foi de 120 dias.

$\mathrm{Na}$ avaliação dos cortes histopatológicos no microscópio com fluorescência, foi evidenciada a presença das CTMs marcadas com o nanocristal Qtracker 655 no grupo GA (Fig. 1), porém não foi observada a sua presença no GB, o que evidencia a não migração das células marcadas. Este dado, entretanto, não é suficiente para concluir que as CTMs não têm potencial de migração. Estudos mais complexos devem ser realizados para a confirmação ou não do potencial de migração dessas células nessas circunstâncias. A obtenção das CTMs marcadas com o nanocristal Qtracker 655 após sete dias de seu implante foi baseada em estudos anteriores, que também demonstraram a marcação das CTMs após uma semana do seu implante no defeito ósseo tibial (Oliveira et al., 2010). Outro estudo que demonstra o potencial de marcação do nanocristal por longos períodos avaliou o tempo de manutenção de fluorescência de CTMs marcadas com o nanocristal in vitro e observou sua marcação por mais de 50 dias (Oliveira et al., 2009).

\section{CONCLUSÃO}

O nanocristal Qtracker 655 foi eficaz na marcação das CTMs derivadas da medula óssea equina. Observou-se fluorescência das CTMs implantadas no grupo tratado após sete dias do tratamento. Não foram encontrados pontos fluorescentes nos membros contralaterais (grupo controle), o que evidencia ausência de migração das CTMs marcadas.

\section{AGRADECIMENTOS}

Ao Conselho Nacional de Desenvolvimento Científico e Tecnológico (CNPq), pela concessão de bolsa de doutorado para o autor principal. 


\section{REFERÊNCIAS}

ALVES, A.L.G.; STEWART, A.A.; DUDHIA, J. et al. Cell-based therapies for tendon and ligament injuries. Vet. Clin. Equine., v.27, p.315333, 2011.

CARVALHO, A.M.; YAMADA, A.L.M.; GOLIM, M.A. et al. Evaluation of mesenchymal stem cell migration after equine tendonitis therapy. Equine Vet. J., doi: 10.1111/evj.12173 2013.

DE MATTOS CARVALHO, A.; BADIAL, P.R.; ALVAREZ, L.E.C. et al. Equine tendonitis therapy using mesenchymal stem cells and platelet concentrates: a randomized controlled trial. Stem cell rese. \& therapy., v.4, p.85, 2013.

COLLINS, M.C.; GUNST, P.R.; CASCIO, W.E. et al. Labeling and imaging mesenchymal stem cells with quantum dots. Methods Mol. Biol., v.906, p.199-210. 2012.

GODWIN, E.E.; YOUNG, N.J.; DUDHIA, J. et al. Implantation of bone marrow-derived mesenchymal stem cells demonstrates improved outcome in horses with overstrain injury of the superficial digital flexor tendon. Equine Vet. J., v.44, p.25-32, 2012.

GUEST, D.J.; SMITH, M.R.W.; ALLEN, W.R. Monitoring the fate of autologous and allogeneic mesenchymal progenitor cells injected into the superficial digital flexor tendon of horses: Preliminary study. Equine Vet. J., v.40, p.178181, 2008.

MAIA, L.; LANDIM-ALVARENGA, F.C.; MOTA, L.S.L.S. et al. Immunophenotypic, Immunocytochemistry, Ultrastructural, and Cytogenetic Characterization of Mesenchymal Stem Cells From Equine Bone Marrow. Microsc. Res. Techniq., v.76, p.618-624, 2013.

MULLER-BORER, B.J.; COLLINS, M.C.; GUNST, P.R. et al. Quantum dot labeling of mesenchymal stem cells. J. Nanobiotechnol., v.5, p.9, 2007.
OLIVEIRA, D.M.; ALMEIDA, B.O.; MARTI, L.C. et al. Labeling of human mesenchymal stem cells with quantum dots allows tracking of transplanted cells engrafted in infarcted pig hearts. Einstein., v.7, p.284-289, 2009.

OLIVEIRA, G.K.; RAISER, A.G.; OLSSON, D. et al. Células-tronco mononucleares autólogas e proteínas óssea morfogenética na cicatrização de defeitos tibiais experimentalmente induzidos em cães. Arq. Bras. Med. Vet. Zootec., v.62, p.72-79, 2010.

OLIVEIRA, P.G.G; ALVES, A.L.G; CARVALHO, A.M. et al. Uso de células mononucleares da medula óssea no tratamento de tendinites induzidas experimentalmente em equinos. Arq. Bras. Med. Vet. Zootec., v.63, p.1391-1398, 2011.

ROSEN, A.B.; KELLY, D.J.; SCHULDT, A.J. et al. Finding fluorescent needles in the cardiac haystack: tracking human mesenchymal stem cells labeled with quantum dots for quantitative in vivo three-dimensional fluorescence analysis. Stem Cell., v.25, p.2128-2138. 2007.

SATAKE, K.; LOU, J.; LENKE, L.G. Migration of mesenchymal stem cells through cerebrospinal fluid into injured spinal cord tissue. In: $49^{\text {th }}$ Annual Meeting of the Orthopaedic Society, Luisiânia, 2003. p.78.

SMITH, R.K.W.; KORDA, M.; BLUNN, G.W. et al. Isolation and implantation of autologous equine mesenchymal stem cells from bone marrow into the superficial digital flexor tendon as a potential novel treatment. Equine Vet. J., v.35, p.99-102, 2003.

YAMADA, A.L.M.; ALVES, A.L.G.; HUSSNI, C.A. et al. Comparison of different doses of collagenase-induced equine tendonitis: clinical and ultrasonographic study. Cienc. Rural., v.39, p.1124-1130, 2009. 